\title{
CLINICAL MANAGEMENT FOR EPIDERMOLYSIS BULLOSA DYSTROPHICA
}

\author{
Thais M. OLIVEIRA ${ }^{1}$, Vivien T. SAKAI ${ }^{1}$, Liliani A. CANDIDO ${ }^{1}$, \\ Salete M. B. SILVA ${ }^{2}$, Maria Aparecida A. M. MACHADO ${ }^{3}$
}

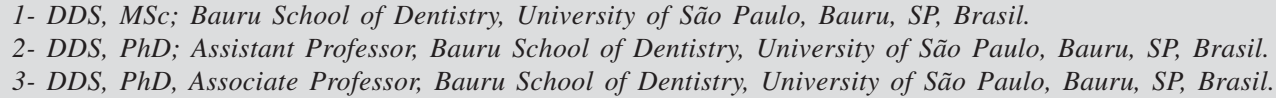

Corresponding address: Dra. Maria Ap. A.M. Machado - Disciplina de Odontopediatria, Faculdade de Odontologia de Bauru, Universidade de São Paulo. Alameda Dr. Octávio Pinheiro Brisolla 9-75 - 17012-901, Bauru, SP, Brasil - Phone: 5514 3235-8218 - e-mail: mmachado@fob.usp.br

Received: August 17, 2007 - Modification: August 31, 2007 - Accepted: September 20, 2007

\begin{abstract}
$E$ pidermolysis bullosa (EB) consists of a group of genetic hereditary disorders in which patients frequently present fragile skin and mucosa that form blisters following minor trauma. More than 20 subtypes of EB have been recognized in the literature. Specific genetic mutations are well characterized for most the different EB subtypes and variants. The most common oral manifestations of EB are painful blisters affecting all the oral surfaces. Dental treatment for patients with EB consists of palliative therapy for its oral manifestations along with typical restorative and periodontal procedures. The aim of this article is to describe two dental clinical treatments of recessive dystrophic EB cases and their specific clinical manifestations. The psychological intervention required during the dental treatment of these patients is also presented.
\end{abstract}

Uniterms: Epidermolysis bullosa. Oral manifestations. Dental caries.

\section{INTRODUCTION}

Epidermolysis bullosa (EB) comprises a group of genetically determined skin fragility disorders characterized by blistering of the skin and mucosa following mild mechanical trauma ${ }^{18,20,21}$. Approximately 400,000-500,000 people are affected worldwide and no definitive treatments have yet been developed ${ }^{8,7}$. EB is classified into distinct subtypes depending on the location of blistering within the cutaneous dermal-epidermal basement membrane zone. Ten genes are known to harbor mutations in the major types of $\mathrm{EB}$, and the level of expression of these genes within the cutaneous basement membrane zone and in extracutaneous tissues, as well as the types and combinations of the mutations, explain, in general terms, the phenotypic variability $^{22}$.

The dystrophic forms of EB are characterized by deformities of the skin including coalescence of the fingers, blistering, scarring, nail changes and milia formation, and have either autosomal recessive or dominant inheritance ${ }^{16,20}$. In the most severe cases, scars may cause either ankyloglossia or microglossia ${ }^{3,18}$.

The major dental complication of EB in general is the increased risk of caries ${ }^{3}$. Wright et al. ${ }^{24}$ have shown that the prevalence of caries, scored as DMFS (decayed, missing, filled surfaces), was significantly higher in the junctional (mean 58.6) and recessive dystrophic (mean 37.6) EB types than in controls (mean 23.2). It has been hypothesized that excessive caries is a result of the presence and severity of the soft tissue involvement, which leads to alteration in diet (soft and frequently carbohydrate food); increased oral clearance time (secondary to limited tongue mobility and vestibular constriction); creation of an abnormal tooth/soft tissue relationship (i.e., buccal and lingual mucosa, which is firmly positioned against the tooth); and prevents normal oral hygiene measures ${ }^{3,10}$.

Dental treatment is aimed at avoiding the formation of new bullae during perioperative management, and the choice of anesthetic method is one of the main issues for dentists and anesthesiologists ${ }^{21}$. Special dental concerns involve the use of soft toothbrushes and irrigation techniques. Purée diets are recommended because of the lesions involving the oral mucosa and esophagus. There is also a need for diet supplements, such as vitamins, proteins and iron in order to avoid anemia. The use of corticoids, vitamin $\mathrm{E}$ and immunosuppressive drugs have also been suggested for the treatment of $\mathrm{EB}^{1,2,14,19}$.

The aim of this case report is to describe the oral health condition of two patients with recessive dystrophic EB and the treatments provided. 


\section{CASE REPORT}

\section{Case 1}

A 16-year-old Caucasian girl with recessive dystrophic EB presented to our dental school for routine treatment. According to the clinical interview, hemorrhagic blisters in the mouth had been detected since early infancy. With the patient's growing and physical development, lesions extended to the face, feet and hands. Due to her great difficulty in performing adequate oral hygiene, almost all of her teeth had been destroyed by caries lesions and were covered with dental plaque (Figure 1A and B). Her oldest sister had died one year before as a consequence of the same disease.

The patient's mental status was appropriate for her age. However, her physical development was delayed and her weight and height were compatible with that expected for a 9 year-old child. During physical examination, several blisters were observed in several areas of the body, and they quickly appeared right after mild pressure on her lips. Her fingernails and toenails were absent and her hands showed some degree of deformity. Her tongue presented no papillae. She also

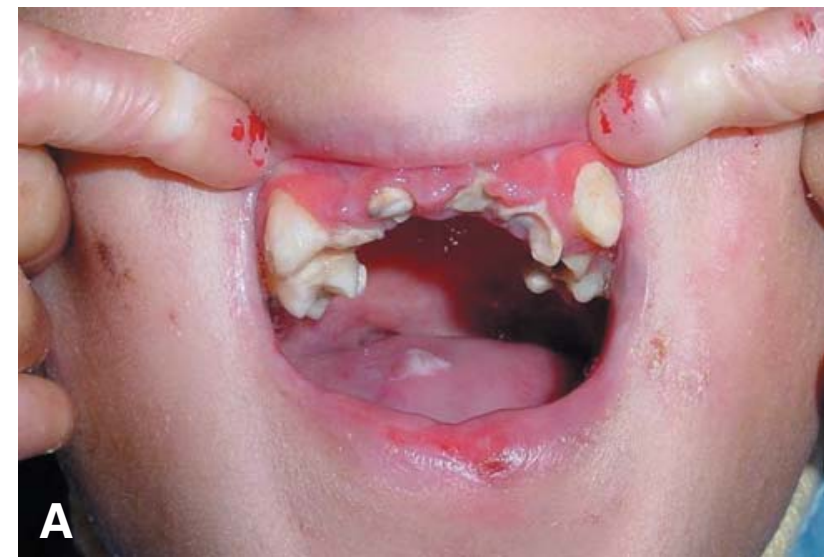

presented ankyloglossia and microstomia, probably due to secondary scars from repeated episodes of blistering and subsequent healing.

After evaluation of the panoramic radiograph (Figure 2) and intraoral examination, a treatment plan was established. Extraction of maxillary right first molar, first premolar, lateral incisor and central incisor, maxillary left central incisor, lateral incisor and first premolar, mandibular left first molar, mandibular right first and second premolars and first molar, and restorative treatment of second premolar, canine, mandibular left first premolar and mandibular right lateral incisor were recommended. At beginning of the dental treatment the patient was poorly cooperative and did not permit even a simple dental examination. The option for dental extraction as part of the treatment plan was based on the clinical limitations associated with the patient's disease. Microstomia, blister formation and the poor patient cooperation all together made the surgical procedures even more difficult and challenging. Dental plaque was disclosed and the patient was taught how to improve her oral hygiene through better brushing techniques and the additional use of a $0.12 \%$ chlorhexidine solution applied topically with a

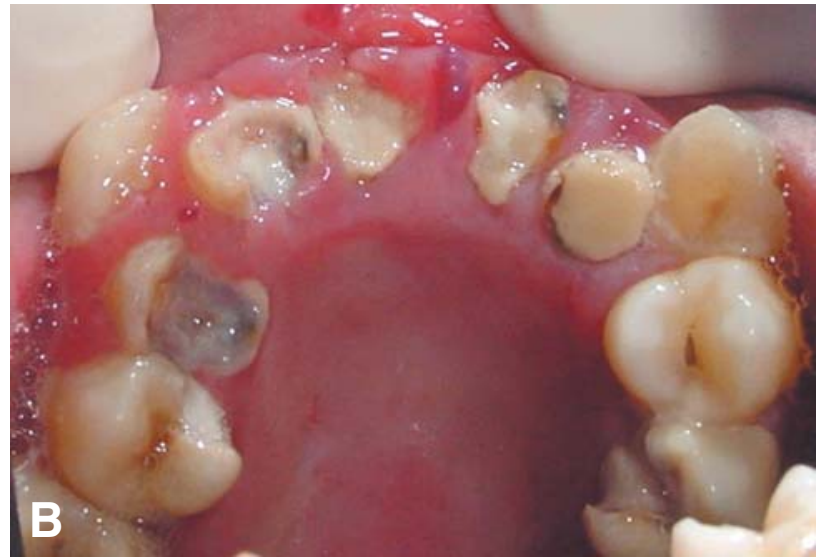

FIGURE 1- $A=$ Frontal view of open mouth with patient's help. The limitation of mouth opening was a consequence of microstomia. $\mathrm{B}=$ Maximal upper occlusal view

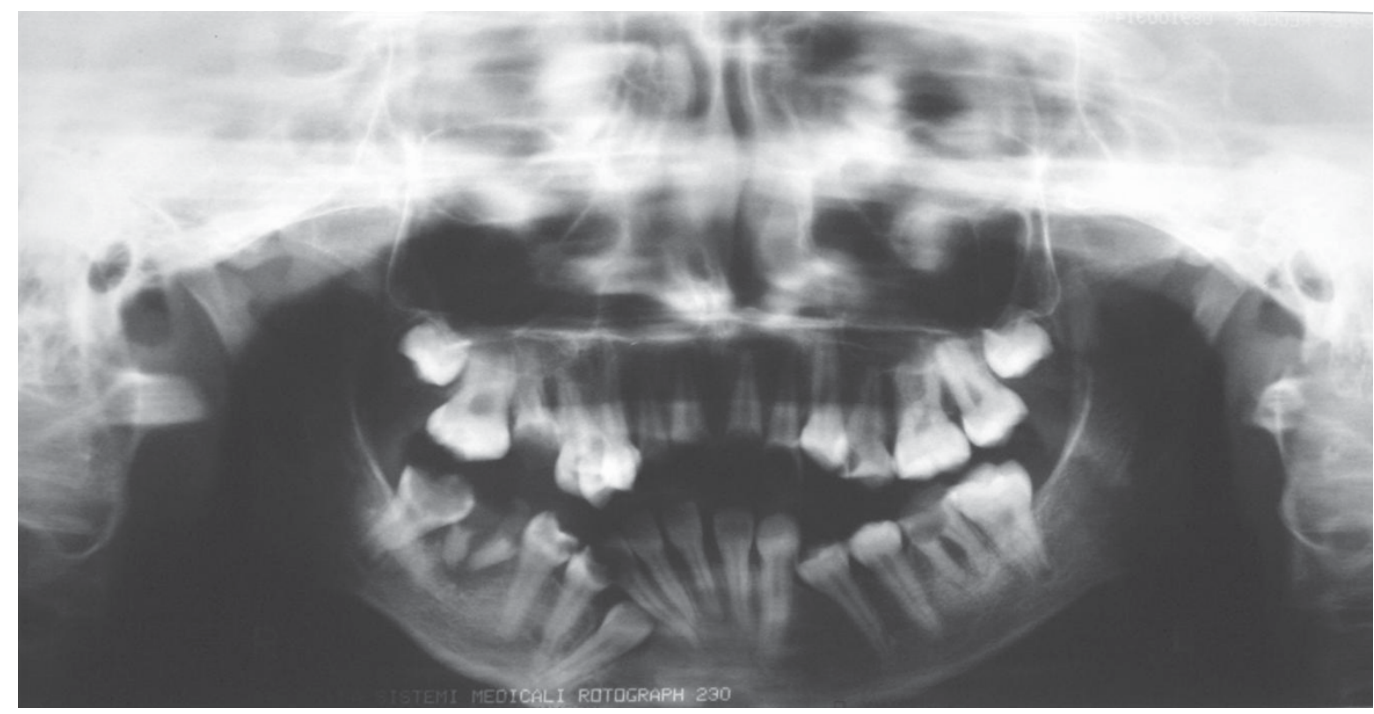

FIGURE 2- Panoramic radiograph showing the oral health status 
cotton bud after lunch and at bed time for 7 days.

Following the patient's conditioning therapy, the surgical procedures were carried out in 5 weekly appointments (Figure 3A). At all extraction sections, first a topical local anesthetic was applied for 4 minutes. Right after, one cartridge $(1.8 \mathrm{~mL})$ of local anesthetic solution, $2 \%$ mepivacaine with 1:100,000 adrenaline, was infiltrated. During the application of the local anesthetic solution, blister formation occurred. To avoid trauma to the fragile oral mucosa, precautions were adopted, including the use of gentle pressure during the surgeries and no suture usage. After each extraction, the healing process was very rapid and the patient did not complain about any pain (Figure 3B).

A prosthetic appliance with two central incisors was prepared to replace the four maxillary anterior teeth, and it was delivered after the maxillary extractions had been completed (Figure 4). The delay for delivering the appliance was purposeful, in order to give the patient motivation to cooperate with the required surgical and restorative procedures. The restorative treatment using glass ionomer cement was accomplished within 5 weeks.

The patient was followed for 3 years for control of the prosthetic appliance and oral health.

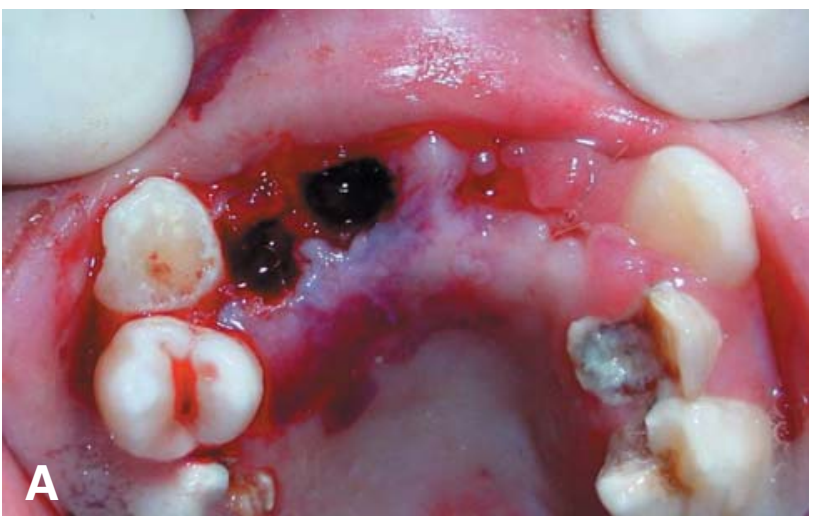

\section{Case \#2}

A 5-year-old African-American boy was admitted to treatment, because of white spot lesions, at our institution. The patient had had recessive dystrophic EB since birth. There was no family history of EB. His mother's pregnancy had been full term and uncomplicated. He presented ulceration, lesions and blister formation on the hands, feet, knees, trunk, elbows, face, scalp, lips and inside the mouth. The fingers of both hands had become fused.

Intraorally, blisters of various sizes were seen on the tongue, gingiva and oral mucosa. The gingival tissue was red, edematous and ulcerated. The mucous membrane was extremely friable, easily yielding sloughs when touched. The teeth had advanced white spot lesions, and there was deposition of dental plaque on all teeth (Figure 5). The patient reported feeding difficulties only when the blisters were very painful.

After the contact with the patient's physician, a panoramic radiograph was taken and a treatment plan was developed (Figure 6). Dental plaque and white spot lesions control was weekly recommended. Thus, conditioning sessions were adopted in order to obtain the patient's trust. Dental plaque was controlled with professional prophylaxis and use of $0.12 \%$ chlorhexidine gel applied topically. Fluoridated varnish was applied on white spot lesions.

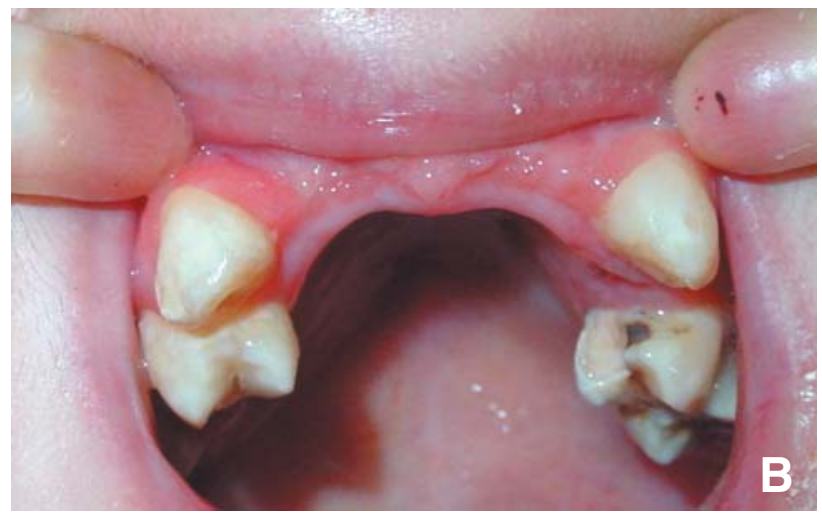

FIGURE 3- $A=$ Immediate (maxillary right central and lateral incisors) and 7-day (maxillary left central and lateral incisors) postoperative aspect. Note the hemorrhagic blisters on the lip and palate after surgery. B= Oral aspect 1 month after the first surgical procedure

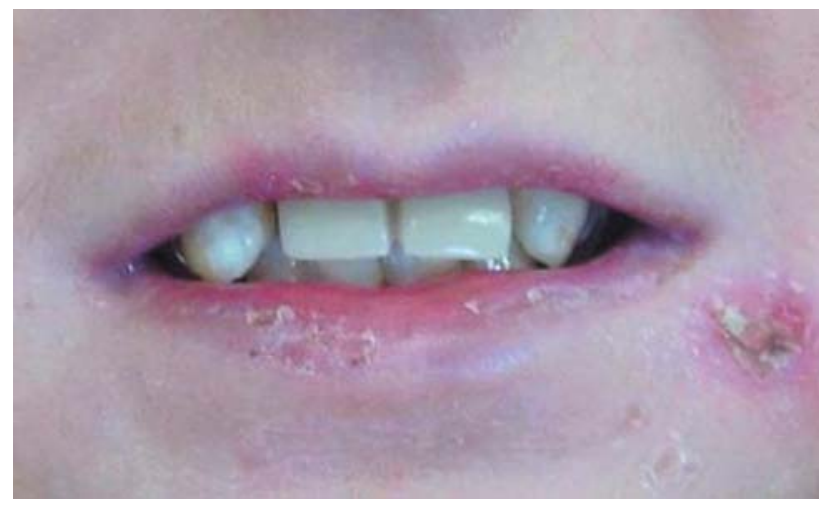

FIGURE 4- Frontal view of the patient's face partially showing the prosthetic appliance with two upper incisors 


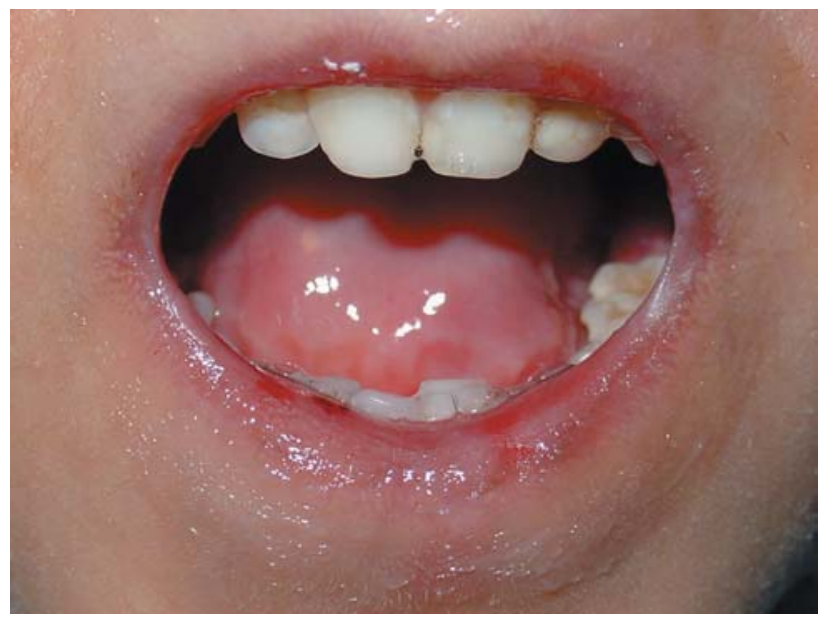

FIGURE 5- Frontal view of open mouth. The limitation of mouth opening was a consequence of the microstomia

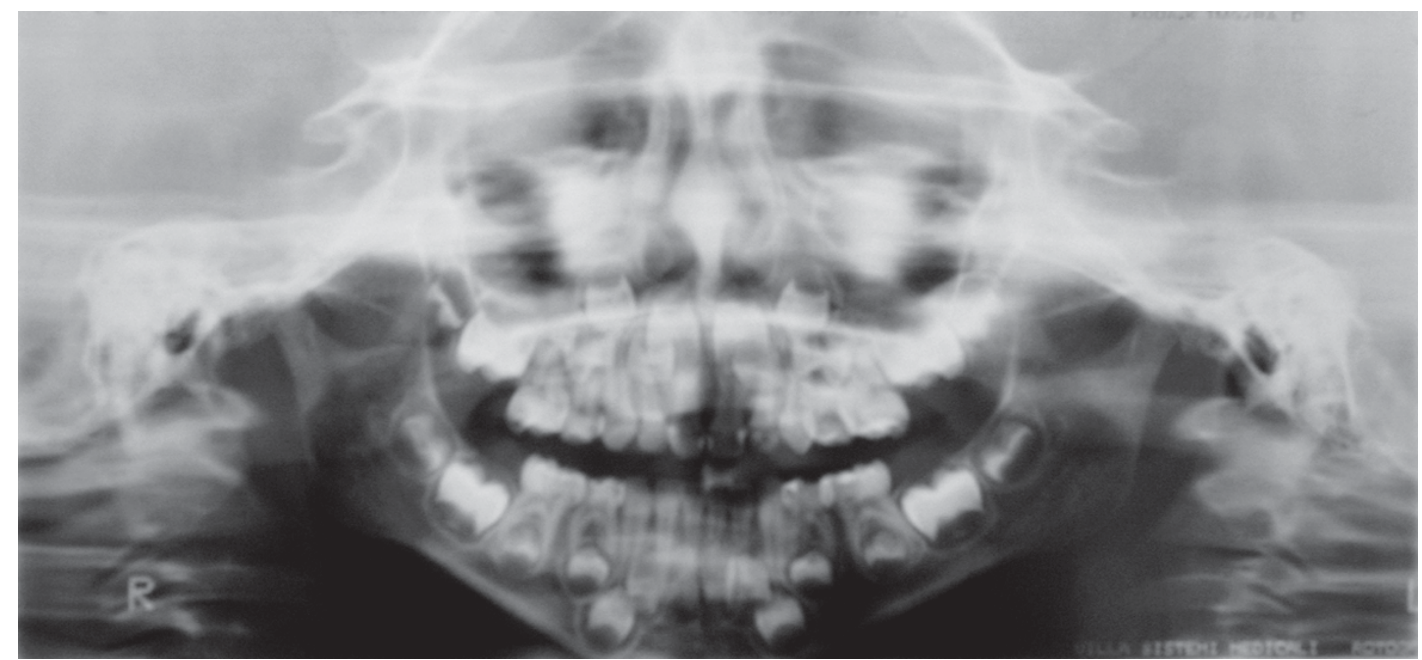

FIGURE 6- Panoramic radiograph showing the oral health status

The patient has been under control of oral health since he was 2 years old. He uses a $0.05 \%$ fluoridated solution applied topically with a cotton bud on all teeth once daily. At the moment, the patient is 5 years old.

\section{DISCUSSION}

Physiopathologically, EB is caused by anomalous adhesion of the epithelial components. This occurs at different levels, depending on the subtype of EB. In the junctional and dystrophic forms, the separation occurs through the lucent lamina of the basement membrane and the lamina densa, respectively. Due to the lack of cohesion, blisters form following minor trauma. In both cases presented in this work, blisters formed after mild pressure on the mouth $^{15,16}$ and during administration of local anesthetic solution $^{11}$ (Case 1). Although the clinical manifestations suggested EB diagnosis in both cases presented hereby, confirmation was granted by histopathologic study conducted at Lauro de Souza Lima Hospital, Bauru, SP,
Brazil.

In some subtypes of EB, the oral cavity is susceptible to injury. Erosions, blisters and eventually a tongue without papillae are observed in addition to ankyloglossia and microstomia ${ }^{2,12,17,23,24}$. In our cases, the presence of polymorphic lesions involving the oral mucous membrane and tongue were present. The loss of tongue papillae and ankyloglossia could be related both to the long duration of the disease in these patients and to the fact that they suffer from the most severe form of epidermolysis ${ }^{10,13}$.

The treatment for patients with EB is multidisciplinary and, unfortunately, no specific therapeutic regimen can cure the disease $\mathrm{e}^{7,8}$. Secondary infections must be treated with topical and/or systemic antibiotics and a protein-rich diet, iron and zinc must be provided ${ }^{11,14,16,19}$. While systemic treatment remains primarily palliative, it is possible to prevent destruction and subsequent loss of the dentition by means of appropriate interventions and dental therapy ${ }^{7,16}$.

The dental treatment of the patient of Case 1 was not very simple, whereas the patient of Case 2 required only preventive measures. In Case 1, the patient's physical and 
psychological suffering resulted in very reluctant behavior and in a special ability to involve her parents. Parents' indulgence, a common characteristic in cases like this in which an actual life-threatening condition is present, has contributed significantly to her poor oral status ${ }^{4,8,15}$.

Treatment modalities that help decreasing patient's anxiety are advisable. They provide safer treatment and help reducing the consequent effects of trauma to the soft tissues from dental treatment. This could also diminish the number of exposures. Although moderate sedation was not used for treating the patient of Case 1, it is a good option for management of oral condition of anxious patients ${ }^{5,6}$ because it allows for completion of a larger number of procedures in single session, thus reducing the number of visits, repeated oral trauma and bullous formation. Hence, the amount of resulting scarring and constrictures, especially in a very apprehensive patient with acute dental anxiety, is reduced ${ }^{5}$. Moreover, regular dental evaluation and treatment is imperative and should be instituted as early as possible ${ }^{9,15}$, similarly to what has been done for the patient of Case 2 .

\section{CONCLUSION}

Dentists should be aware of the presentation of EB to assist in early diagnosis and to provide the patient with the proper preventive and/or restorative treatment. The present cases emphasize the importance for recognition of EB and the need for multidisciplinary treatment of affected patients. Due to the great difficulty and risk of providing dental treatment to patients with EB, prevention of caries and periodontal disease must be emphasized at a very young age.

\section{REFERENCES}

1- Blanchet-Bardon C, Bohbot S. Using Urgotul dressing for the management of epidermolysis bullosa skin lesions. J Wound Care. 2005;14(10):490-1, 494-6.

2- Brain JH, Paul BF, Assad AD. Periodontal plastic surgery in a dystrophic epidermolysis bullosa patient: review and case report. J Periodontol. 1999;70(11):1392-6.

3- Cagirankaya LB, Hatipoglu MG, Katipoglu H. Localized epidermolysis bullosa simplex with generalized enamel hypoplasia in a child. Pediatr Dermatol. 2006;23(2):167-8.

4- Camm JH, Gray SE, Mayes TC. Combined medical-dental treatment of an epidermolysis bullosa patient. Spec Care Dent. 1991;11(4):14850 .

5- Campiglio GL, Pajardi G, Rafanelli G. A new protocol for the treatment of hand deformities in recessive dystrophic epidermolysis bullosa (13 cases). Ann Chir Main Memb Super. 1997;16(2):91-100.

6- Doyle L, Colletti JE. Pediatric procedural sedation and analgesia. Pediatr Clin North Am. 2006;53(2):279-92.

7- Ferrari S, Pellegrini G, Mavilio F, De Luca M. Gene therapy approaches for epidermolysis bullosa. Clin Dermatol. 2005;23(4):4306.
8- Ferrari S, Pellegrini G, Matsui T, Mavilio F, De Luca M. Gene therapy in combination with tissue engineering to treat epidermolysis bullosa. Expert Opin Biol Ther. 2006;6(4):367-78.

9- Harel-Raviv M, Bernier S, Raviv E, Gornitsky M. Oral epidermolysis bullosa in adults. Spec Care Dent. 1995;15(4):144-8.

10- Harris JC, Bryan RA, Lucas VS, Roberts GJ. Dental disease and caries related microflora in children with dystrophic epidermolysis bullosa. Pediatr Dent. 2001;23(5):438-43.

11 - Hochberg MS, Vazquez-Santiago IA, Sher M. Epidermolysis bullosa: a case report. Oral Surg Oral Med Oral Pathol. 1993;75(1):54-

12- Kostara A, Roberts GJ, Gelbier M. Dental maturity in children with dystrophic epidermolysis bullosa. Pediatr Dent. 2000;22(5):3858 .

13- Marin-Bertolin S, Amaya Valero JV, Neira Gimenez C, Marquina Vila P, Amorrortu-Velayos J. Surgical management of hand contractures and pseudosyndactyly in dystrophic epidermolysis bullosa. Ann Plast Surg. 1999;43(5):555-9.

14- Olsen CB, Bourke LF. Recessive dystrophic epidermolysis bullosa. Two case reports with 20-year follow-up. Aust Dent J. 1997;42(1):1-

15- Pekiner LC, Cruz RA, Abou-Id LR, Brini LN, Moreira LS. Clinical evaluation of patients with epidermolysis bullosa: review of the literature and case reports. Spec Care Dent. 2004;24(1):22-7.

16- Pekiner FN, Yucelten D, Ozbayrak S, Sezen EC. Oral-clinical findings and management of epidermolysis bullosa. J Clin Pediatr Dent. 2005;30(1):59-65.

17- Quiñónez GBM, Oliveira TM, Candido LA, Machado MAAM. Conducta clínica em um caso de epidermólisis ampollosa distrófica recesiva. Pediatr. (Assunción) 2003;30(1):39-43

18 - Serrano-Martínez MC, Bagán JV, Silvestre FJ, Viguer MT. Oral lesions in recessive dystrophic epidermolysis bullosa. Oral Dis. 2003;9(5):264-8.

19- Silva LC, Cruz RA, Abou-Id LR, Brini LN, Moreira LS. Clinical evaluation of patients with epidermolysis bullosa: review of the literature and case reports. Spec Care Dent. 2004;24(1):22-7.

20- Solovan C, Ciolan M, Olariu L. The biomolecular and ultrastructural basis of epidermolysis bullosa. Acta Dermatovenerol Alp Panonica Adrait. 2005;14(4):127-35

21 - Toda Y, Uokoyama M, Morimatsu H, Nakatsuka H, Takeuchi M, Katayama $\mathrm{H}$, et al. General anesthesia in a patient with dystrophic epidermolysis bullosa. J Anesth. 2006;20(2):138-40.

22 - Varki R, Sadowski S, Pfendner E, Uitto J. Epidermolysis bullosa. I. Molecular genetics of the junctional and hemidesmosomal variants. J Med Genet. 2006;43(8):641-52.

23 - Wright JT, Johnson L, Fine JD. Developmental defects of enamel in human with hereditary epidermolysis bullosa. Arch Oral Biol. 1993;38(11):945-55.

24- Wright JT, Fine JD, Johnson L. Dental caries risk in hereditary epidermolysis bullosa. Pediatr Dent. 1994;16(6):427-32. 